\section{Research Square}

Preprints are preliminary reports that have not undergone peer review.

They should not be considered conclusive, used to inform clinical practice, or referenced by the media as validated information.

\title{
Population-based Respiratory Syncytial Virus Hospitalization Disease Burden and Cost Effectiveness of Palivizumab Prophylaxis in Infants with Hemodynamically Significant Congenital Heart Diseases
}

Robin Hay-son Chen ( $\nabla$ chenhsr@ha.org.hk)

Queen Mary Hospital, Hong Kong https://orcid.org/0000-0003-3060-4270

Susan Shui-seng Chiu

University of Hong Kong Li Ka Shing Faculty of Medicine

So-Iun Lee

Queen Mary Hospital

Tak-Cheung Yung

Queen Mary Hospital

Research article

Keywords: heart failure, cyanotic heart disease, pulmonary hypertension

Posted Date: July 7th, 2020

DOI: https://doi.org/10.21203/rs.3.rs-38998/v1

License: (c) (i) This work is licensed under a Creative Commons Attribution 4.0 International License. Read Full License 


\section{Abstract \\ Background}

Infants with hemodynamically significant congenital heart disease (HsCHD) are at risk of respiratory syncytial virus hospitalization (RSVh) and Palivizumab has been shown to be effective in preventing RSVh in regions with a distinct RSV season. However, the incidence of RSVh in HsCHD patients and the cost-effectiveness of Palivizumab in regions with year-round RSV activity is largely unknown.

\section{Methods}

All HsCHD patients < 12 months of age referred to the only tertiary pediatric cardiology center in Hong Kong during 1 Jan 2014 to 31 Dec 2016 were included. RSVh rate, Palivizumab efficacy and cost-effectiveness were assessed using a 5 or 6 monthly dose regimen starting from first hospital discharge.

\section{Results}

Twenty-six RSVh (11\%) were identified out of $236 \mathrm{HsCHD}$ patients. 222 patients were included for further analysis of Palivizumab efficacy and cost-effectiveness. The number needed to treat to prevent RSVh using 5 and 6 dose regimen was 54.9 and 38 , respectively, with a wide year-to-year variation from 25 to 166.6. RSVh cost without Palivizumab was $\$ 379,436$; while palivizumab program cost for 5 and 6 dose were $\$ 727,481$ and $\$ 849,888$ respectively. Incremental cost-effective ratio per hospital admission prevented was $\$ 85,937$ and $\$ 80,419$ for 5 and 6 dose regimen, respectively, with a wide year-to-year variation from $\$ 40,410$ to $\$ 277,367$.

\section{Conclusion}

This is one of the first population-based studies in infants with HsCHD demonstrating a high RSVh burden in a region with round the year circulation of RSV. Palivizumab program was assessed to be not cost-effective in preventing RSVh in such a locality.

\section{Introduction}

Respiratory syncytial virus (RSV) infection is the leading cause of respiratory infection in young infants worldwide.[1-4] Infants with underlying medical conditions, including hemodynamically significant congenital heart diseases (HsCHD) are at increased risk of RSV associated hospitalization (RSVh), morbidity and even mortality.[5-11] Unlike influenza virus, there is yet no effective active immunization against RSV. The only option for RSV prevention is passive immunization with Palivizumab, a humanized monoclonal antibody against the F-glycoprotein of RSV. The efficacy of a 5 consecutive monthly Palivizumab injection regimen during RSV season in the US has been shown to be effective in preventing $\mathrm{RSVh}$ in $\mathrm{HsCHD}$, with a 45\% relative reduction of RSVh.[12] A similar regimen of palivizumab is recommended for infants with HsCHD immediately before and during the RSV season in their first year of life by the American Academy of Paediatrics (AAP).[13] However, in subtropical regions like Hong Kong, the RSV season is often quite prolonged and lacks a discrete peak. Palivizumab is not routinely given to infants with HsCHD in Hong Kong. There is no data on RSVh for infants with HsCHD in Hong Kong and the efficacy and cost effectiveness of a Palivizumab program for $\mathrm{HsCHD}$ under such circumstances are largely unknown. Therefore, we aimed to elucidate the burden of RSVh in this group of patients in Hong Kong and using the time of infection to assess the proportion of infants who might have benefited from a palivizumab prophylaxis program. We then assessed the potential cost effectiveness of a population-wide palivizumab program for infants with HsCHD in Hong Kong.

\section{Materials And Methods}

The annual live birth cohort of Hong Kong was around 60,000 per year.[14] The Department of Paediatric Cardiology at Queen Mary Hospital is the only tertiary pediatric Cardiac Centre in Hong Kong where $98 \%$ of all infants with HsCHD requiring transcatheter or surgical interventions are referred since the only team of pediatric cardiothoracic surgeons in Hong Kong are based in Queen Mary Hospital. All patients born between 1 Jan 2014 and 31 Dec 2016 and referred to our Cardiac Centre were retrieved from a central computerized database, Clinical Data Analysis and Reporting System. Patients with a diagnosis of CHD under International Classification of Diseases, 9th, Revision, Clinical Modification (ICD-9-CM), were selected and their medical record reviewed in detail to identify infants who qualified for inclusion. Due to potential fluctuations in RSV activity in different years, a 3-year study period was used to cover a spectrum of RSV activity intensity. In brief, should there be a low RSV activity intensity, a cost-effective analysis for any preventive measures would bias towards being ineffective and vice versa. The study was approved by the Institutional Review Board of the University of Hong Kong / Hospital Authority Hong Kong West Cluster.

Patients with HsCHD were identified from record review by a pediatric cardiologist (RHSC) and included in the study. CHD was classified as hemodynamically significant based on the definition from the AAP updated policy statement for Palivizumab prophylaxis 2014[13]. HsCHD was 
defined as CHD associated with 1. heart failure requiring surgical treatment (our group also included those with heart failure requiring catheterbased interventional treatment), 2. pulmonary hypertension (PHT) and 3. cyanotic heart disease. Exclusion criteria included 1. patients with HsCHD, but at the same time fulfilling other established criteria for receiving palivizumab (e.g. premature infants with bronchopulmonary dysplasia with coexisting haemodynamically significant patent ductus arteriosus); 2. critical congenital heart diseases requiring total surgical / catheter intervention either immediately or soon after birth, never discharged from hospital before total correction, and with no significant residual lesions upon discharge; 3. Patients with less than 6 months of follow up period after HsCHD diagnosis .

Data extracted from study patients included, age of diagnosis of HsCHD, date of first hospital discharge after HsCHD diagnosis, body weight on discharge, date of total corrective operation or intervention, HsCHD diagnosis and indication for palivizumab. RSVh within the first year of life in these patients, with the annual rate of RSVh calculated. RSVh was defined as any respiratory symptoms leading to hospital admission in any hospital in Hong Kong with a positive PCR test for RSV. Nasopharyngeal aspiration testing for RSV by PCR was routine in Hong Kong during the study period. Days of hospitalization, pediatric intensive care unit (PICU) admission and days of PICU stay, days of ventilatory care, and significant morbidity and mortality related to RSVh were recorded.

Cost analysis and potential efficacy of palivizumab program

The cost analysis comparing cost of RSVh versus a palivizumab program was performed in the study cohort after excluding patients without a window for palivizumab administration (e.g. patients were never discharged until after surgical total correction). Dollars are expressed in US currency. Cost of RSVh was calculated based on the average daily cost of hospital stay according to data from Hospital Authority, Hong Kong SAR: $\$ 660$ for paediatric general ward and $\$ 3,130$ for PICU.[15] The potential cost of a palivizumab program included the total drug cost plus the RSVh cost that was deemed not preventable by the palivizumab program as described below. Cost calculation was made based on the drug cost of $\$ 935$ per $100 \mathrm{mg}$ vial of palivizumab with a standard dose of $15 \mathrm{mg} / \mathrm{kg}$ given at a monthly basis as per recommended by the AAP policy[13]. Since there is no discrete RSV season locally, the calculation was made based on the first dose of palivizumab being administered upon first hospital discharge after which the diagnosis of HsCHD was made as advocated by the Taiwan group.[16] The RSVh identified in this cohort were deemed to be potentially preventable by palivizumab if it fell within the duration of prophylaxis course up to within 4 weeks after the last presumed dose of palivizumab; RSVh falling outside this period would be regarded as not preventable. The relative reduction of episodes of RSVh and days of RSVh by a Palivizumab program was presumed to be 0.45 and 0.56 respectively based on the study from Felts et al.[12]. Hence the hospital admission prevented (HAP) would be calculated as the number of RSVh potentially preventable multiplied by 0.45 ; while the number of RSVh days preventable would be the number of RSVh days potentially preventable multiplied 0.56 . By the same principle, $44 \%$ (1-0.56) of the days of RSVh potentially preventable would be regarded as Palivizumab failure and the RSVh cost would be included as part of the cost for the Palivizumab program. The cost for a standard 5 dose regimen and an alternative 6 dose regimen was calculated.[16] Due to the conflicting evidence in the efficacy of palivizumab in cyanotic HsCHD, separate cost calculations were made to include only the heart failure and the PHT group. Since there were significant variations in the logistics of administration in different regional hospitals, the administrative cost was not included in the calculation. Cost effectiveness was further analysed using the incremental cost effective ratio (ICER), which was the difference between the cost of the Palivizumab program as stated above and the RSVh cost without a palivizumab program. The ICER would be expressed as ICER per HAP (ICER/HAP), and ICER per days of RSVh prevented.

The potential efficacy of a palivizumab program was assessed by calculating the number needed to treat (NNT) to prevent one episode of RSVh; taking into account the reported relative reduction of RSVh in palivizumab recipient being 0.45.[12]

\section{Results}

The RSV activity intensity during the study period from the Government Public Health Laboratory Centre showed a higher activity in the year 2016. (Fig. 1) [17] There were a total of 991 patients with CHD during the study period. After excluding 157 critical CHD and 598 patients with mild CHD, 236 patients fulfilled the inclusion criteria for HsCHD. Twenty-six episodes (11\%) of RSVh were documented within the first year of life.

Fourteen out of 236 patients were excluded from the cost analysis since they were never discharged before total surgical or interventional correction of their HsCHD and did not satisfy indication for Palivizumab prophylaxis. Two hundred and twenty-two patients (160 with heart failure, 4 with pulmonary hypertension and 58 with cyanotic heart disease.) were identified to be potential candidates for palivizumab prophylaxis. (Fig. 2) Amongst this group, there were 20 RSVh (9\%): 13 (65\%) with heart failure, 6 (30\%) with cyanotic heart disease and only 1 (5\%) had PHT. Table 1 showed the details of all RSVh including the month of hospital admissions, which did not show any obvious seasonality. The median age at RSVh was 6 months (IQR 2 months, range from 2.4-11 months) and the duration of RSVh was 8 days (IQR 19.5 days, range from 1 to 42 days). There was no death. Only 4 patients (25\%) required PICU admission and only one required invasive mechanical ventilation. This was a 5 -month-old patient with heart failure associated with VSD awaiting surgery who was initially admitted for parainfluenza III chest infection followed by nosocomial RSV infection leading to respiratory failure.

Amongst the group with RSVh, 9/20 and 13/20 RSVh were potentially preventable by a 5-dose and a 6-dose palivizumab regimen respectively. Year to year variation in RSVh per 10,000 HsCHD patients, hospitalization days, cost and NNT of the 2 palivizumab regimens are shown in Table 2.

Page $3 / 11$ 
Taking into account of the efficacy of palivizumab, the number needed to treat (NNT) to prevent one RSVh with a 5-dose regimen would be 54.9, and that for a 6-dose regime would be 38.0. A palivizumab program costed significantly more that the hospitalization cost without palivizumab prophylaxis in all three years of the study.

When cyanotic heart disease was excluded from the calculation, 8 and 11 RSVh were potentially preventable by a 5-dose and 6-dose Palivizumab regimen, respectively, in 14 infants. Year to year variation in RSVh per 10,000 HsCHD patients, hospitalization days, cost and NNT of the 2 palivizumab regimens are shown in Table 3. The overall NNT to prevent one RSVh with a 5-dose regimen would be 45.5 and that for a 6-dose regimen would be 33.1. Even when cyanotic heart disease was excluded, a palivizumab program still costed significantly more that the hospitalization cost without palivizumab prophylaxis in all three years of the study. The ICER/HAP were \$ 85,937 and \$ 80,419 for 5 and 6 dose Palivizumab regimen respectively; whereas the ICER/RSVh days prevented was \$2,301 and \$ 4,038 for 5 and 6 dose Palivizumab regimen, respectively. The ICER/HAP by the year are shown in table 4.

\section{Discussion}

We documented very high hospitalization incidence in infants with HsCHD in Hong Kong with prolonged RSV circulation. This hospitalization incidence was higher than that previously documented in Hong Kong infants $<6$ months of age who did not have congenital heart disease.[1] The incidence we reported is at least comparable if not higher than that previously reported in patients with $\mathrm{HsCHD}$.[6, 9, 10, 18] We also documented that infants with HsCHD in Hong Kong were hospitalized for RSV infection in nearly every month of the year.

Palivizumab has been demonstrated to be a reasonably effective immunoprophylaxis in preventing RSVh in patients with HsCHD in North American and European countries where seasonal clustering of RSV is often evident.[12, 19-21] This had resulted in the recommendation from the AAP on a 5 consecutive dose of palivizumab immunoprophylaxis during RSV seasons for patients with HsCHD below 1 year of age.[13] However, such regimen has not been uniformly successful, with persistence of significant RSVh risk being reported despite Palivizumab prophylaxis for patients with $\mathrm{HsCHD}$ in countries with a distinct RSV season.[22] The applicability of the AAP recommendation is even more questionable in subtropical and tropical areas that often lack a defined RSV season.[23-25] Limited studies have tried to elucidate the efficacy of alternative Palivizumab regimens in such countries. Chiu et al from Taiwan reported the use of a novel palivizumab prophylaxis protocol, involving 6 monthly injections commencing right after diagnosis of $\mathrm{HsCHD}$ has been made, and concluded that to be effective in preventing RSVh.[16] However, the study was limited by its low baseline RSVh rate of $4.8 \%$ only from a historical cohort as compared with $11 \%$ of our cohort which is more in line with other published data.[6, 12, 26]

Our 3-year study with a range RSV circulation activity provided a better estimation of the effectiveness of palivizumab prophylaxis in areas without a sharp RSV season. The NNT to prevent 1 RSVh could vary from 35 to as high as 166 in a three-year period, with a very high NNT in 2014 when the RSV activity was the lowest with RSVh rate of $4 \%$ only. This year to year variation of incidence has actually been well reported in subtropical and tropical areas, and could be related to various meteorological factors.[27-30] The overall high NNT and high cost in preventing RSVh with palivizumab could be explained by the year round circulation of RSV activity resulting in a significant proportion of RSVh occurring outside the prophylaxis period.

The high cost of palivizumab is yet another important matter of concern. Rigorous effort has been instigated in addressing the cost-effectiveness of its use in preventing RSVh in patients with HsCHD.[26, 31-40] Unfortunately, only a few studies were focused on this group of patients alone in areas with a distinct RSV season, and none of which were population-based.[26, 31, 33, 40,41] These studies were mainly based on either hypothetical patient cohorts or decision-analysis models using ICER/Quality Adjusted Life year (QALY) to assess cost-effectiveness with an exceedingly wide range reported from $€ 9,259$ to US\$114,337/QALY.[33, 40, 41] Despite a very favorable ICER/QALY was reported by Nuijten et al, a scenario analysis excluding mortality from the model was reported to raise the ICER/QALY significantly from €9,259 to €123,439/QALY.[41] Judging from the fact that the RSV related mortality in this group of patients reported from the REGAL series covers a wide range from 0 to $3.3 \%$, we think using ICER/QALY in hypothetical model may result in significant inaccuracy. Since there was no reported RSV related mortality in our study cohort, we preferred to assess the cost-effectiveness with ICER/HAP, which was probably more appropriate for medical systems with low to minimal RSV related mortality. Furthermore, since the protection against RSVh rendered by palivizumab was not $100 \%$ as reported by Feltes et al[12], unlike many of the aforementioned studies, we have also included in our calculation the cost of RSVh as a result of palivizumab failure. From our results, not only was the cost of US\$85,937/HAP (based on 5-dose regimen) much higher than that reported by Rackhman et al[26], our data also pointed out an important effect of the year-to-year variation in RSV activity on cost-effectiveness with ICER/HAP showing an almost 7fold differences comparing years with lowest and highest RSV activity with a similar number of infants with newly diagnosed HsCHD each year in the population. Judging from our data, albeit a lack of consensus for an acceptable threshold for ICER/HAP, a Palivizumab program is not cost effective in preventing RSVh in patients with HsCHD. On the other hand, other strategies may prove to be more cost effective in reducing RSVh. In our cohort, the mean waiting time for HsCHD patient with heart failure to undergo surgical intervention was 4.3 months. A reduction in this waiting time, and hence the cumulative time at risk of RSVh, can potentially reduce the burden of RSVh. Development of RSV vaccine is certainly another option and numerous vaccine candidates are currently in the pipeline.[42] Once licensed, such vaccines may replace Palivizumab in preventing $\mathrm{RSVh}$ in high risk patients including those with $\mathrm{HsCHD}$.

Page $4 / 11$ 
Our study had several limitations. Firstly, the assessment of efficacy and cost-effectiveness of Palivizumab was based on assumptions of a relative risk reduction in RSVh from published data in regions with distinct RSV seasons rather than from local prospective data with round the year RSV activity. To compensate for the difference in RSV activity, we have factored into the time of infection and considered those infected outside the hypothetical program as prophylaxis failure. Secondly, tangible cost like administrative cost of Palivizumab and non-tangible costs like cares' absence from work were not included in the calculation. However, by only considering drug cost, our data reflected the minimal cost of giving Palivizumab. Finally, since the patient cohort was identified from a database, we might have inadvertently omitted patients who might qualify for Palivizumab if recruited prospectively. An example being patients presented with heart failure and an initial intent for surgery, but in the end did not require surgical intervention. In a prospective study, these patients would be eligible for Palivizumab injection. For that matter, a post-hoc analysis was conducted for all patients classified as mild CHD with RSVh. Amongst this group there were only 2 RSVh and both of which happened beyond 6 months after the diagnosis of CHD was made, making them unpreventable by Palivizumab even if given. Hence including these patients with "borderline" indication would only worsening the ICER/HAP making it even less cost-effective.

Strengths of this study included the data obtained were robust. Firstly, we are the only major pediatric cardiology center that served nearly all pediatric patients with congenital heart disease in Hong Kong. In addition, RSV testing was routine in children with acute respiratory infections and was PCR-based across all hospitals in Hong Kong. Moreover, we have also elected to obtain data over the span of 3 years with wide variation of RSV circulation burden enabling us to assess scenario with a range of RSV activity levels. Lastly, each HsCHD case was intensively reviewed by a pediatric cardiologist, not only relying on diagnostic codes from the database, ensuring correct classification of the patients' cardiac status.

\section{Conclusion}

The RSVh burden in patients with HsCHD in Hong Kong, a subtropical region, was demonstrated to be at least similarly high if not higher as compared with countries with temperate climate. However, a Palivizumab program in this region where there is round the year circulation of RSV was assessed to be not cost-effective in preventing RSVh. To our knowledge this is one of the first population-based cost-effectiveness studies of a palivizumab prophylaxis program in infants with $\mathrm{HsCHD}$ in a subtropical region where there may be year-round RSV circulation.

\section{Declarations}

\section{Acknowledgement}

The authors would like to thank Mr. Wilfred HS Wong for his contribution in data collection and analysis.

Funding: Not applicable.

Competing interest: The authors declare that they have no competing interest

Availability of data and Material: The datasets during and/or analysed during the current study available from the corresponding author on reasonable request

Code availability: Not applicable

\section{Ethics approval:}

This retrospective chart review study involving human participants was in accordance with the ethical standards of the institutional and national research committee and with the 1964 Helsinki Declaration and its later amendments or comparable ethical standards. The study was approved by the Institutional Review Board of the University of Hong Kong / Hospital Authority Hong Kong West Cluster, Hong Kong SAR.

\section{Contributor's Statement}

RHC conceptualized and designed the study, designed the data collection instrument, collected the data, carried out the initial analysis, drafted the initial manuscript, reviewed and revised the manuscript.

SSC conceptualized and designed the study, drafted the initial manuscript, reviewed and revised the manuscript.

SL and TY conceptualized and designed the study, critically reviewed and revised the manuscript for important intellectual content.

All authors approved the final manuscript as submitted and agreed to be accountable for all aspects of the work.

\section{References}

1. Chiu SS, Chan KH, Chen H, Young BW, Lim W, Wong WH, et al. Virologically confirmed population-based burden of hospitalization caused by respiratory syncytial virus, adenovirus, and parainfluenza viruses in children in Hong Kong. Pediatr Infect Dis J. 2010;29(12):1088-92. 
2. Hervas D, Reina J, Yanez A, del Valle JM, Figuerola J, Hervas JA. Epidemiology of hospitalization for acute bronchiolitis in children: differences between RSV and non-RSV bronchiolitis. Eur J Clin Microbiol Infect Dis. 2012;31(8):1975-81.

3. Nair H, Nokes DJ, Gessner BD, Dherani M, Madhi SA, Singleton RJ, et al. Global burden of acute lower respiratory infections due to respiratory syncytial virus in young children: a systematic review and meta-analysis. Lancet. 2010;375(9725):1545-55.

4. Shi T, McAllister DA, O'Brien KL, Simoes EAF, Madhi SA, Gessner BD, et al. Global, regional, and national disease burden estimates of acute lower respiratory infections due to respiratory syncytial virus in young children in 2015: a systematic review and modelling study. Lancet. 2017;390(10098):946-58.

5. Duppenthaler A, Ammann RA, Gorgievski-Hrisoho M, Pfammatter JP, Aebi C. Low incidence of respiratory syncytial virus hospitalisations in haemodynamically significant congenital heart disease. Arch Dis Child. 2004;89(10):961-5.

6. Meberg A, Bruu AL. Respiratory syncytial virus infections in congenital heart defects-hospitalizations and costs. Acta Paediatr. 2006;95(4):404-6.

7. Altman CA, Englund JA, Demmler G, Drescher KL, Alexander MA, Watrin C, et al. Respiratory syncytial virus in patients with congenital heart disease: a contemporary look at epidemiology and success of preoperative screening. Pediatr Cardiol. 2000;21(5):433-8.

8. Butt M, Symington A, Janes M, Steele S, Elliott L, Chant-Gambacort C, et al. Respiratory syncytial virus prophylaxis in children with cardiac disease: a retrospective single-centre study. Cardiol Young. 2014;24(2):337-43.

9. Medrano Lopez C, Garcia-Guereta L, Group CS. Community-acquired respiratory infections in young children with congenital heart diseases in the palivizumab era: the Spanish 4-season civic epidemiologic study. Pediatr Infect Dis J. 2010;29(12):1077-82.

10. Resch B, Kurath-Koller S, Hahn J, Raith W, Kostenberger M, Gamillscheg A. Respiratory syncytial virus-associated hospitalizations over three consecutive seasons in children with congenital heart disease. Eur J Clin Microbiol Infect Dis. 2016;35(7):1165-9.

11. Thorburn K. Pre-existing disease is associated with a significantly higher risk of death in severe respiratory syncytial virus infection. Arch Dis Child. 2009;94(2):99-103.

12. Feltes TF, Cabalka AK, Meissner HC, Piazza FM, Carlin DA, Top FH Jr, et al. Palivizumab prophylaxis reduces hospitalization due to respiratory syncytial virus in young children with hemodynamically significant congenital heart disease. J Pediatr. 2003;143(4):532-40.

13. American Academy of Pediatrics Bronchiolitis Guidelines C. Updated guidance for palivizumab prophylaxis among infants and young children at increased risk of hospitalization for respiratory syncytial virus infection. Pediatrics. 2014;134(2):415-20.

14. Hong Kong Monthly Digest of Statistics. Census and Statistics Department, Hong Kong Department. Dec 2018.

15. Fees. and Charges webpage, Hospital Authority, Hong Kong. https://.asp?Content_ID=10045\&Lang=ENG.

16. Chiu SN, Wang JN, Fu YC, Chung HT, Chang LY, Wu MH, et al. Efficacy of a Novel Palivizumab Prophylaxis Protocol for Respiratory Syncytial Virus Infection in Congenital Heart Disease: A Multicenter Study. J Pediatr. 2018;195:108 - 14 e1.

17. Centre of Health Protection. Government of Hong Kong SAR. Statistics on Laboratory Surveillance. https://www.chp.gov.hk/en/statistics/data/10/641/642/2278.html.

18. Kristensen K, Stensballe LG, Bjerre J, Roth D, Fisker N, Kongstad T, et al. Risk factors for respiratory syncytial virus hospitalisation in children with heart disease. Arch Dis Child. 2009;94(10):785-9.

19. Frogel M, Nerwen C, Cohen A, VanVeldhuisen P, Harrington M, Boron M, et al. Prevention of hospitalization due to respiratory syncytial virus: results from the Palivizumab Outcomes Registry. J Perinatol. 2008;28(7):511-7.

20. Ozyurt A, Narin N, Baykan A, Argun M, Pamukcu O, Zararsiz G, et al. Efficacy of palivizumab prophylaxis among infants with congenital heart disease: A case control study. Pediatr Pulmonol. 2015;50(10):1025-32.

21. Wegzyn C, Toh LK, Notario G, Biguenet S, Unnebrink K, Park C, et al. Safety and Effectiveness of Palivizumab in Children at High Risk of Serious Disease Due to Respiratory Syncytial Virus Infection: A Systematic Review. Infect Dis Ther. 2014;3(2):133-58.

22. Manzoni P, Paes B, Lanctot KL, Dall'Agnola A, Mitchell I, Calabrese S, et al. Outcomes of Infants Receiving Palivizumab Prophylaxis for Respiratory Syncytial Virus in Canada and Italy: An International, Prospective Cohort Study. Pediatr Infect Dis J. 2017;36(1):2-8.

23. Chiu SN, Shao PL, Chen HC, Lin MT, Huang LM, Kao FY, et al. Risk of Respiratory Syncytial Virus Infection in Cyanotic Congenital Heart Disease in a Subtropical Area. J Pediatr. 2016;171:25-30 e1.

24. Hsu CH, Lin CY, Chi H, Chang JH, Hung HY, Kao HA, et al. Prolonged seasonality of respiratory syncytial virus infection among preterm infants in a subtropical climate. PLoS One. 2014;9(10):e110166.

25. Reese PE, Marchette NJ. Respiratory syncytial virus infection and prevalence of subgroups A and B in Hawaii. J Clin Microbiol. 1991;29(11):2614-5.

26. Rackham OJ, Thorburn K, Kerr SJ. The potential impact of prophylaxis against bronchiolitis due to the respiratory syncytial virus in children with congenital cardiac malformations. Cardiol Young. 2005;15(3):251-5.

27. Darniot M, Pitoiset C, Milliere L, Aho-Glele LS, Florentin E, Bour JB, et al. Different meteorological parameters influence metapneumovirus and respiratory syncytial virus activity. J Clin Virol. 2018;104:77-82.

Page 6/11 
28. Gamba-Sanchez N, Rodriguez-Martinez CE, Sossa-Briceno MP. Epidemic activity of respiratory syncytial virus is related to temperature and rainfall in equatorial tropical countries. Epidemiol Infect. 2016;144(10):2057-63.

29. Hervas D, Reina J, Hervas JA. Meteorologic conditions and respiratory syncytial virus activity. Pediatr Infect Dis J. 2012;31(10):e176-81.

30. Kamigaki T, Chaw L, Tan AG, Tamaki R, Alday PP, Javier JB, et al. Seasonality of Influenza and Respiratory Syncytial Viruses and the Effect of Climate Factors in Subtropical-Tropical Asia Using Influenza-Like Illness Surveillance Data, 2010-2012. PLoS One. 2016;11(12):e0167712.

31. Harris KC, Anis AH, Crosby MC, Cender LM, Potts JE, Human DG. Economic evaluation of palivizumab in children with congenital heart disease: a Canadian perspective. Can J Cardiol. 2011;27(4):523 e11-5.

32. Nuijten M, Lebmeier M, Wittenberg W. Cost effectiveness of palivizumab for RSV prevention in high-risk children in the Netherlands. J Med Econ. 2009;12(4):291-300.

33. Yount LE, Mahle WT. Economic analysis of palivizumab in infants with congenital heart disease. Pediatrics. 2004;114(6):1606-11.

34. Nuijten MJ, Wittenberg W, Lebmeier M. Cost effectiveness of palivizumab for respiratory syncytial virus prophylaxis in high-risk children: a UK analysis. Pharmacoeconomics. 2007;25(1):55-71.

35. Resch B, Gusenleitner W, Nuijten MJ, Lebmeier M, Wittenberg W. Cost-effectiveness of palivizumab against respiratory syncytial viral infection in high-risk children in Austria. Clin Ther. 2008;30(4):749-60.

36. Resch B, Sommer C, Nuijten MJ, Seidinger S, Walter E, Schoellbauer V, et al. Cost-effectiveness of palivizumab for respiratory syncytial virus infection in high-risk children, based on long-term epidemiologic data from Austria. Pediatr Infect Dis J. 2012;31(1):e1-8.

37. Wang D, Cummins C, Bayliss S, Sandercock J, Burls A. Immunoprophylaxis against respiratory syncytial virus (RSV) with palivizumab in children: a systematic review and economic evaluation. Health Technol Assess. 2008;12(36):iii. 1-86.

38. Ambrose CS, Chen X, Kumar VR. A population-weighted, condition-adjusted estimate of palivizumab efficacy in preventing RSV-related hospitalizations among US high-risk children. Hum Vaccin Immunother. 2014;10(10):2785-8.

39. Bentley A, Filipovic I, Gooch K, Busch K. A cost-effectiveness analysis of respiratory syncytial virus (RSV) prophylaxis in infants in the United Kingdom. Health Econ Rev. 2013;3(1):18.

40. Schmidt R, Majer I, Garcia Roman N, Rivas Basterra A, Grubb E, Medrano Lopez C. Palivizumab in the prevention of severe respiratory syncytial virus infection in children with congenital heart disease; a novel cost-utility modeling study reflecting evidence-based clinical pathways in Spain. Health Econ Rev. 2017;7(1):47.

41. Nuijten M, Lebmeier M, Wittenberg W. Cost effectiveness of palivizumab in children with congenital heart disease in Germany. J Med Econ. 2009;12(4):301-8.

42. Graham BS. Vaccine development for respiratory syncytial virus. Curr Opin Virol. 2017;23:107-12.

\section{Tables}

Table 1

Details of all hospitalization associated with respiratory syncytial virus infection 


\begin{tabular}{|c|c|c|c|c|c|c|c|c|c|c|}
\hline $\begin{array}{l}\text { Date } \\
\text { of } \\
\text { Birth } \\
\text { (yyyy- } \\
\text { mm- } \\
\text { dd) }\end{array}$ & $\begin{array}{l}\text { Principal } \\
\text { CHD } \\
\text { diagnosis }\end{array}$ & $\begin{array}{l}\text { Indication } \\
\text { for } \\
\text { palivizumab }\end{array}$ & $\begin{array}{l}\text { Age at } \\
\text { RSVh } \\
\text { (months) }\end{array}$ & $\begin{array}{l}\text { Month } \\
\text { of } \\
\text { RSVh }\end{array}$ & $\begin{array}{l}\text { RSVh } \\
\text { potentially } \\
\text { preventable } \\
(5 \text { doses)* }\end{array}$ & $\begin{array}{l}\text { RSVh } \\
\text { potentially } \\
\text { preventable } \\
(6 \text { doses)* }\end{array}$ & $\begin{array}{l}\text { Length } \\
\text { of } \\
\text { RSVh }\end{array}$ & $\begin{array}{l}\text { Duration } \\
\text { of PICU } \\
\text { stay } \\
\text { (days) }\end{array}$ & $\begin{array}{l}\text { Duration of } \\
\text { CPAP } \\
\text { /Invasive } \\
\text { ventilations } \\
\text { (days) }\end{array}$ & remark \\
\hline $\begin{array}{l}2014- \\
02-11\end{array}$ & TOF & Cyano & 8 & Oct & no & no & 10 & & & \\
\hline $\begin{array}{l}2014- \\
05-04\end{array}$ & PDA & $\mathrm{HF}$ & 5 & Sept & yes & yes & 23 & & & $\begin{array}{l}\text { nosocomial } \\
\text { norovirus } \\
\text { infection } \\
\text { lengthening } \\
\text { the stay }\end{array}$ \\
\hline $\begin{array}{l}2014- \\
12-18\end{array}$ & VSD & PHT & 11 & Nov & no & no & 9 & & & $\begin{array}{l}\text { Also } \\
\text { parainfluenza } \\
\text { II +ve }\end{array}$ \\
\hline $\begin{array}{l}2015- \\
01-01\end{array}$ & TOF & Cyano & 6 & Jul & no & yes & 2 & & & \\
\hline $\begin{array}{l}2015- \\
02-12\end{array}$ & VSD & $\mathrm{HF}$ & 11 & Feb & no & no & 8 & & & \\
\hline $\begin{array}{l}2015- \\
02-23\end{array}$ & VSD & $\mathrm{HF}$ & 2.8 & May & yes & yes & 44 & & & $\begin{array}{l}\text { Prolonged } \\
\text { hospitalization } \\
\text { due to tube } \\
\text { feeding }\end{array}$ \\
\hline $\begin{array}{l}2015- \\
03-18\end{array}$ & VSD & $\mathrm{HF}$ & 5 & Sept & yes & yes & 2 & & & \\
\hline $\begin{array}{l}2015- \\
06-08\end{array}$ & $\begin{array}{l}\text { DORV } \\
\text { subaortic } \\
\text { VSD, CoA }\end{array}$ & $\mathrm{HF}$ & 2.4 & Aug & yes & yes & 7 & & & \\
\hline $\begin{array}{l}2015- \\
09-03\end{array}$ & VSD & $\mathrm{HF}$ & 5 & Feb & yes & yes & 42 & 32 & $4 / 8$ & $\begin{array}{l}\text { Admitted for } \\
\text { parainfluenza } \\
\text { III infection, } \\
\text { followed by } \\
\text { nosocomial } \\
\text { RSV infection }\end{array}$ \\
\hline $\begin{array}{l}2015- \\
09-09\end{array}$ & TAPVD & $\mathrm{HF}$ & 7 & May & yes & yes & 11 & & & \\
\hline $\begin{array}{l}2015- \\
12-11\end{array}$ & $\begin{array}{l}\text { Shone } \\
\text { complex }\end{array}$ & $\mathrm{HF}$ & 6 & June & no & yes & 2 & & & \\
\hline $\begin{array}{l}2015- \\
12-18\end{array}$ & TOF & Cyano & 7 & Aug & no & no & 2 & & & \\
\hline $\begin{array}{l}2016- \\
01-06\end{array}$ & TOF & Cyano & 6 & Jul & no & yes & 6 & & & \\
\hline $\begin{array}{l}2016- \\
03-12\end{array}$ & AVSD & $\mathrm{HF}$ & 6 & Sept & yes & yes & 19 & 14 & & \\
\hline $\begin{array}{l}2016- \\
05-18\end{array}$ & VSD & $\mathrm{HF}$ & 6.5 & June & no & no & 28 & 5 & $3 / 0$ & \\
\hline $\begin{array}{l}2016- \\
07-12\end{array}$ & $\begin{array}{l}\text { complex } \\
\text { cyanotic } \\
\text { heart }\end{array}$ & Cyano & 4 & Dec & yes & yes & 8 & & & \\
\hline $\begin{array}{l}2016- \\
07-22\end{array}$ & ASD & $\mathrm{HF}$ & 7 & Mar & no & yes & 37 & 31 & $6 / 0$ & $\begin{array}{l}\text { persistent HF } \\
\text { post } \\
\text { operatively }\end{array}$ \\
\hline $\begin{array}{l}2016- \\
09-02\end{array}$ & $\begin{array}{l}\text { Complex } \\
\text { cyanotic } \\
\text { heart }\end{array}$ & Cyano & 11 & May & no & no & 4 & & & \\
\hline $\begin{array}{l}2016- \\
12-14\end{array}$ & VSD & $\mathrm{HF}$ & 5 & Jan & yes & yes & 5 & & & $\begin{array}{l}\text { persistent HF } \\
\text { post } \\
\text { operatively }\end{array}$ \\
\hline $\begin{array}{l}2016- \\
07-08\end{array}$ & VSD & $\mathrm{HF}$ & 7 & Feb & no & no & 1 & & & \\
\hline
\end{tabular}


ASD: atrial septal defect; AVSD: atrioventricular septal defect; CHD: congenital heart disease; CPAP: continuous positive airway pressure; CoA: coarctation of the aorta; cyano: cyanotic congenital heart disease, DORV: double outlet right ventricle; HF: heart failure; PDA: patent ductus arteriosus; PICU: pediatric intensive care unit; PHT: pulmonary hypertension; RSVh: respiratory syncytial virus associated hospitalization; TAPVD: total anomalous pulmonary venous drainage; TOF: tetralogy of Fallot; VSD: ventricular septal defect

* Respiratory syncytial virus associated hospitalization potentially preventable by palivizumab using 5 or 6 consecutive monthly dose (refer to text for detail description)

Table 2

The number of hospitalization, hospitalization rate, cumulative days of hospitalization and the number needed to treat to prevent hospitalization and cost associated with respiratory syncytial virus by the year

\begin{tabular}{|c|c|c|c|c|c|c|c|}
\hline Year & $\begin{array}{l}\text { No. of } \\
\text { HSCHD }\end{array}$ & $\begin{array}{l}\text { No. of RSVh } \\
\text { [RSVh per } 10,000 \\
\text { HsCHD patients] }\end{array}$ & $\begin{array}{l}\text { Days } \\
\text { of } \\
\text { RSVh }\end{array}$ & $\begin{array}{l}\text { NNT to prevent } 1 \text { RSVh } \\
\text { for } 5 \text { dose / } 6 \text { dose } \\
\text { palivizumab regimen }\end{array}$ & $\begin{array}{l}\text { Cost of } \\
\text { RSVh (\$) }\end{array}$ & $\begin{array}{l}\text { Cost of Palivizumab } 5 \\
\text { dose regimen (\$) }\end{array}$ & $\begin{array}{l}\text { Cost of Palivizumab } 6 \\
\text { dose regimen }(\$)\end{array}$ \\
\hline 2014 & 75 & 3 [400.0] & 42 & 166.6 / 166.6 & 27,462 & 180,014 & 242,720 \\
\hline 2015 & 79 & 9 [1139.2] & 120 & 35 / 25 & 157,641 & 248,565 & 301,454 \\
\hline 2016 & 68 & 8 [1176.5] & 108 & $50 / 30.3$ & 194,333 & 298,901 & 305,714 \\
\hline Total & 222 & 20 [900.9] & 270 & $54.9 / 38$ & 379,436 & 727,480 & 849,888 \\
\hline
\end{tabular}

HsCHD, haemodynamically significant congenital heart disease; NNT, number needed to treat; RSVh, respiratory syncytial virus associated hospitalization

Table 3

The number of hospitalization, hospitalization rate, cumulative days of hospitalization and the number needed to treat to prevent hospitalization and cost associated with respiratory syncytial virus by the year, excluding cyanotic heart diseases

\begin{tabular}{|c|c|c|c|c|c|c|c|}
\hline Year & $\begin{array}{l}\text { No. of } \\
\text { HSCHD }\end{array}$ & $\begin{array}{l}\text { No. of RSVh } \\
\text { [RSVh per } 10,000 \\
\text { HsCHD patients] }\end{array}$ & $\begin{array}{l}\text { Days } \\
\text { of } \\
\text { RSVh }\end{array}$ & $\begin{array}{l}\text { NNT to prevent } 1 \text { RSVh } \\
\text { for } 5 \text { dose / } 6 \text { dose } \\
\text { palivizumab regimen }\end{array}$ & $\begin{array}{l}\text { Cost of } \\
\text { RSVh (\$) }\end{array}$ & $\begin{array}{l}\text { Cost of Palivizumab } 5 \\
\text { dose regimen (\$) }\end{array}$ & $\begin{array}{l}\text { Cost of Palivizumab } 6 \\
\text { dose regimen }(\$)\end{array}$ \\
\hline 2014 & 56 & 2 [357.1] & 32 & $100 / 100$ & 20,923 & 134,168 & 170,668 \\
\hline 2015 & 64 & $7[1,093.8]$ & 116 & $28.6 / 23.8$ & 155,026 & 212,257 & 248,025 \\
\hline 2016 & 45 & 5 [1111.1] & 90 & $52.6 / 34.5$ & 182,564 & 245,160 & 225,157 \\
\hline Total & 166 & 14 [843.4] & 239 & 45.5 / 33.1 & 358,513 & 591,585 & 643,850 \\
\hline
\end{tabular}

HsCHD, haemodynamically significant congenital heart disease; NNT, number needed to treat; RSVh, respiratory syncytial virus associated hospitalization

Table 4

Cost effectiveness analysis by incremental cost-effective ratio by the year 


\begin{tabular}{|c|c|c|c|c|}
\hline Year & $\begin{array}{l}\text { ICER/HAP } \\
\text { (5 dose) }\end{array}$ & $\begin{array}{l}\text { ICER/HAP } \\
\text { (6 dose) }\end{array}$ & $\begin{array}{l}\text { ICER/day of RSVh prevented } \\
\text { (5 dose) }\end{array}$ & $\begin{array}{l}\text { ICER/day of RSVh prevented } \\
\text { (6 dose) }\end{array}$ \\
\hline & US\$ & US\$ & US\$ & US\$ \\
\hline $2014(n=75)$ & 277,367 & 277,367 & 11,825 & 11,825 \\
\hline $2015(n=79)$ & 40,411 & 45,655 & 1,530 & 2,335 \\
\hline $2016(n=68)$ & 77,382 & 49,457 & 5836 & 2650 \\
\hline
\end{tabular}

ICER: incremental cost-effective ratio, HAP: hospital admission prevented, RSVh: hospitalization associated with respiratory syncytial virus infection.

\section{Figures}

\section{Respiratory syncytial virus detected in Hong Kong (2014 - 2016)}

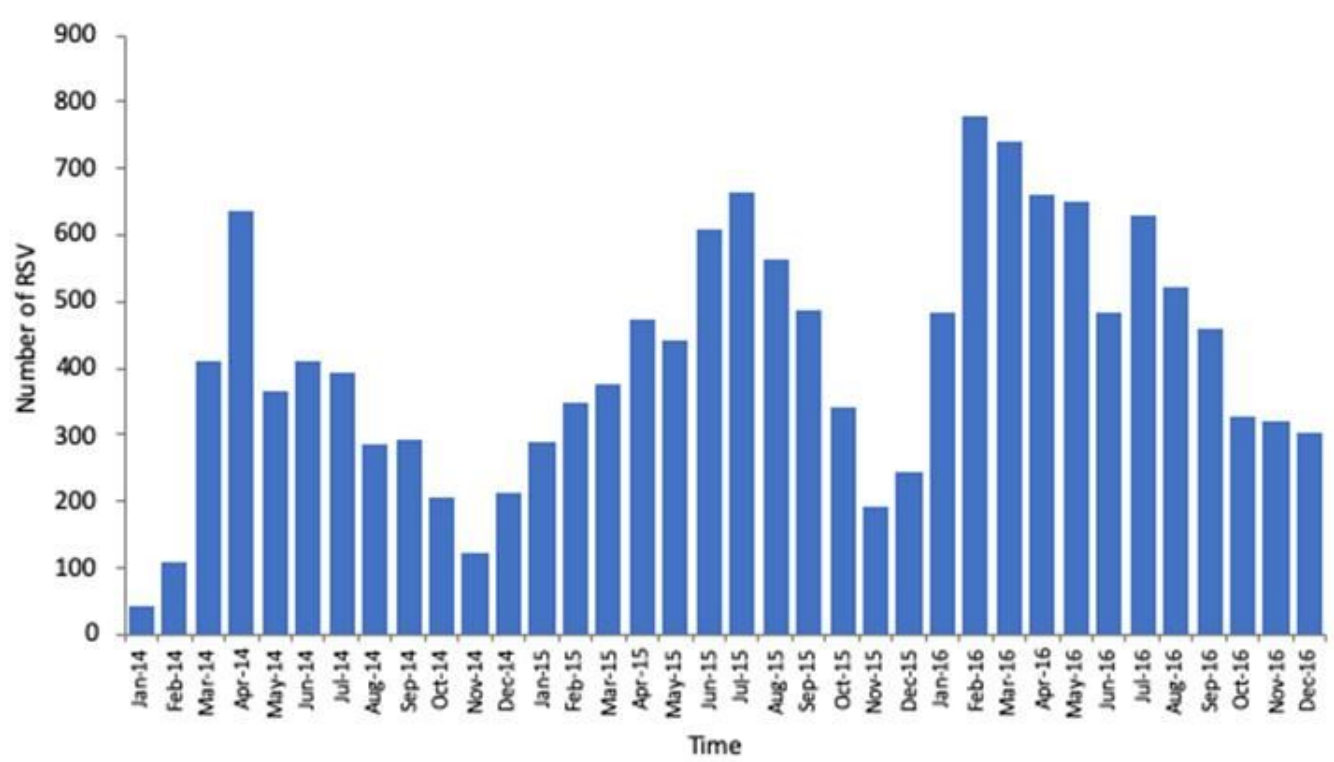

\section{Figure 1}

RSV activity during the study period from 2014 to 2016 from the Hong Kong SAR Government Public Health Laboratory Centre data accessed from Centre for Health Protection in January 2019. 


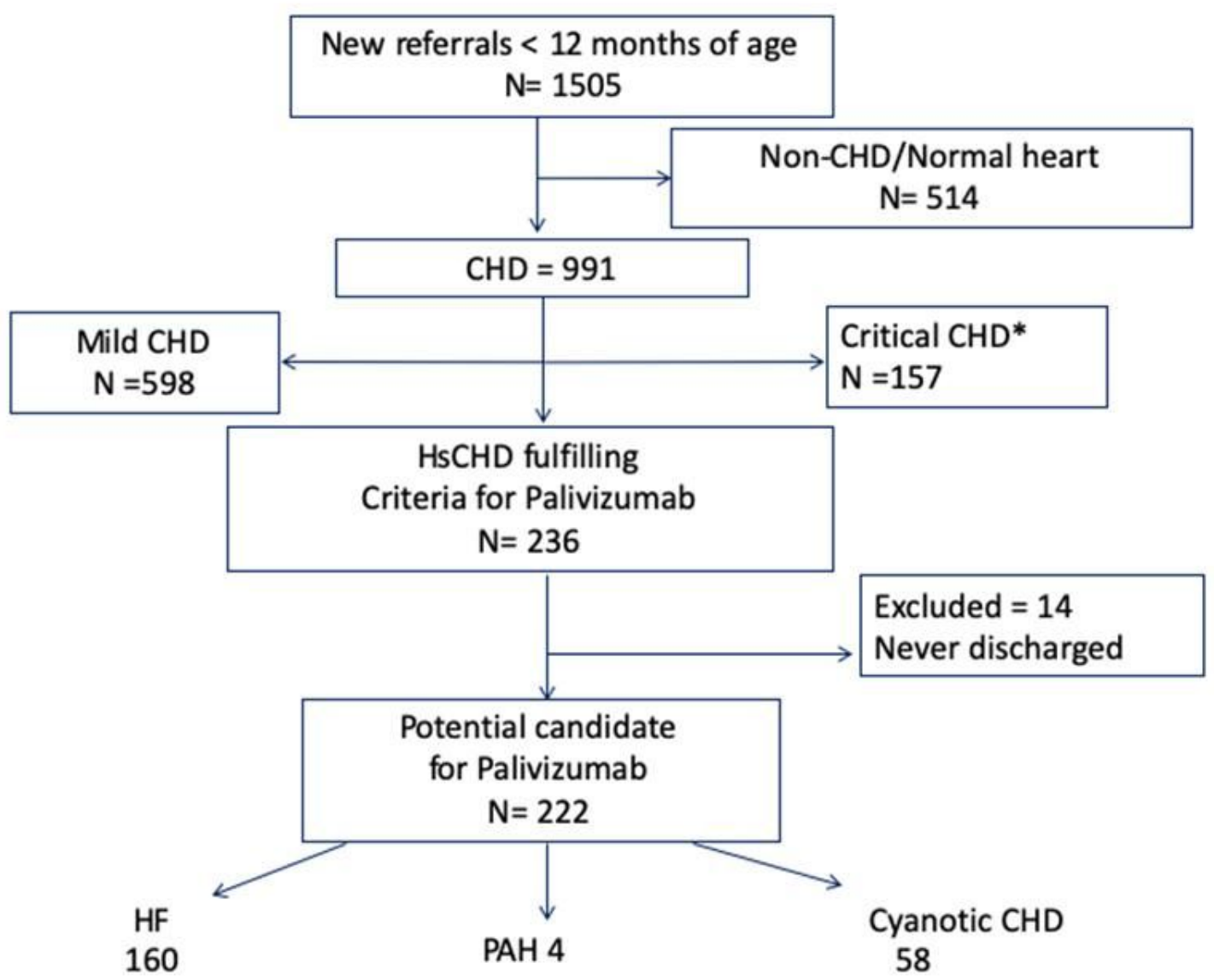

Figure 2

Identification of patients with HsCHD eligible for Palivizumab during the study period CHD: congenital heart disease, HF: heart failure, HsCHD: hemodynamically significant congenital heart disease, $\mathrm{PAH}$ : pulmonary arterial hypertension. *Critical CHD requiring immediate or early operation before 1 st discharge 